\title{
Vaccine Development Throughout History
}

\author{
Amr Saleh ${ }^{1}$, Shahraz Qamar ${ }^{2}$, Aysun Tekin ${ }^{3}$, Romil Singh ${ }^{3}$, Rahul Kashyap ${ }^{3}$ \\ 1. Faculty of Medicine, Mansoura University, Mansoura, EGY 2. Post-baccalaureate Research Education Program, Mayo \\ Clinic, Rochester, USA 3. Critical Care, Mayo Clinic, Rochester, USA
}

Corresponding author: Aysun Tekin, aysunvergili@hotmail.com

\begin{abstract}
The emergence of the coronavirus disease 2019 (COVID-19) pandemic has made us appreciate how important it is to quickly develop treatments and save lives. The race to develop a vaccine for this novel coronavirus began as soon as the pandemic emerged. Time was the only limiting factor. From the first vaccine developed in 1796 against smallpox to the latest COVID-19 vaccine, there have been several vaccines that have reduced the burden of disease, with the associated mortality and morbidity. Over the years we have seen many new advancements in organism isolation, cell culture, whole-genome sequencing, and recombinant nuclear techniques. These techniques have greatly facilitated the development of vaccines. Each vaccine has its own development story and there is much wisdom to be gained from learning about breakthroughs in vaccine development.
\end{abstract}

Categories: Internal Medicine, Infectious Disease, Epidemiology/Public Health

Keywords: vaccine development, infectious and parasitic diseases, smallpox, polio, rabies, cholera, covid-19

\section{Introduction And Background}

Although inoculation practices were started more than 500 years ago, the term vaccine was first described in the 18th century by Edward Jenner. It is derived from Vacca, a Latin word for cow. Jenner inoculated an eightyear-old boy with cowpox lesions from the hands of milkmaids in 1796 . This ultimately conferred immunity against smallpox. After 80 years, Louis Pasteur was instrumental in developing a live attenuated vaccine against rabies in humans which was highly successful. In the 19th century, we witnessed the evolution of germ theory through the discovery of numerous microorganisms by Koch. By the mid-20th century, after the introduction of attenuated toxins (toxoids) the first generation of vaccines were developed. Through this development, it was possible to make vaccines for diphtheria and tetanus. In the 1930s, major advances in lab techniques allowed the cultivation of viruses on the chorioallantoic membranes of chick embryos. This led to the development of influenza and yellow fever vaccines. The evolution of cell culture 15 years later led to the creation of the polio vaccine, and this marked the beginning of the golden age of vaccines. During this period a series of important vaccines like the measles, mumps, rubella, and varicella vaccines were developed. The introduction of recombinant DNA and whole-genome sequencing techniques were major milestones in vaccine development. It gave researchers the tools to develop new vaccines against pathogens, which was not possible before. We aim to cover the timeline and development of most of the vaccines

Review began 07/02/2021 Review ended 07/11/2021 Published 07/26/2021

(c) Copyright 2021

Saleh et al. This is an open access article distributed under the terms of the Creative Commons Attribution License CC-BY 4.0., which permits unrestricted use, distribution, and reproduction in any medium, provided the original author and source are credited. 


\section{Cureus}

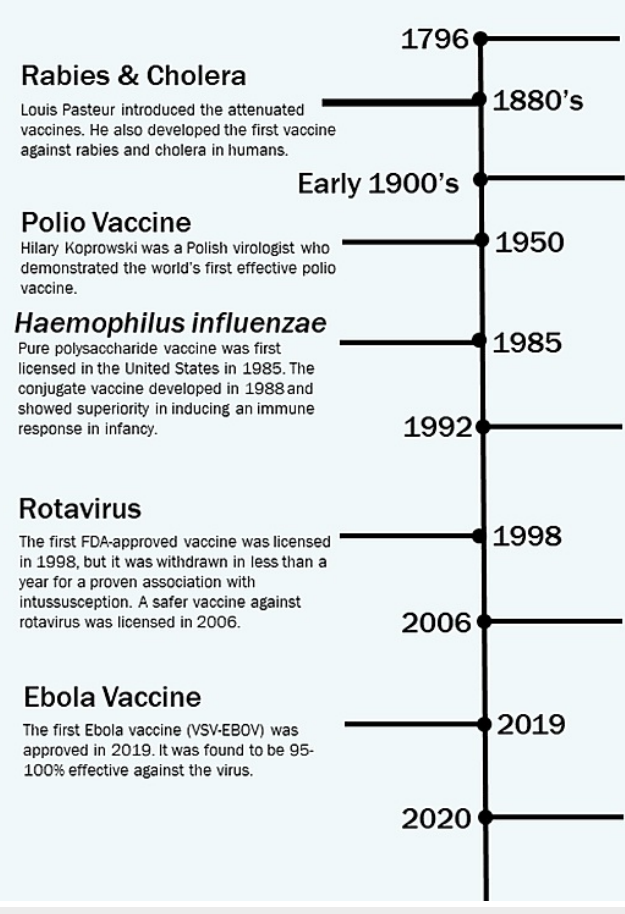

FIGURE 1: Vaccine history timeline.
Smallpox Vaccine

dward Jenner, often called "the father of

列

The introduction of toxoid vaccines (e.g., tetanus,

- The cultivation of viruses on the chorioallantois membranes of chick embryos and the development the Influenza and yellow fever vaccines.

Hepatitis A 1992.

\section{HPV Vaccine}

The first $\mathrm{HPV}$ vaccine became available in 2006. More than 120 million doses have been administered since

COVID-19 Vaccine
on 2 December 2020, the Pfizer-Biontech vaccine became the first vaccine to be approved for COVID-19. As of June 2021 , more than 2.5 billion doses of various COVID -19 vaccines have been administered.

COVID-19, coronavirus disease 2019; FDA, U.S. Food and Drug Administration; HPV, human papillomavirus

\section{Review}

\section{Smallpox}

Smallpox is one of the oldest known infectious diseases. It has caused hundreds of millions of deaths. The earliest written records of this disease go back to China in the 4th century. Some studies postulate that there were smallpox-like rashes found on Egyptian mummies suggesting that it may even go back at least 3000 years [4]. In 1980, World Health Organization (WHO) declared smallpox to be the first disease to be eradicated worldwide because of aggressive immunization efforts.

The earliest documented trials of variolation were in China and India during the 16th century. This was achieved by the inoculation of smallpox pus or scabs either by a nasal or cutaneous route. During the smallpox outbreak worldwide, early inoculation trials were carried out in Britain and colonial Massachusetts in 1721. Also, there had been reports of inoculations from the Ottoman Empire and North Africa. Although the origins of inoculation are not definite, whether it arose from Asia or Africa, the practice of vaccination was first introduced by Edward Jenner in 1796 [5]. He observed that the milkmaids who had cowpox lesions were immune against smallpox infection. He then exposed a young boy to the milkmaids' lesions and observed that the boy got immunity against smallpox. He extended this practice to more children and similar outcomes were recorded [6]. Since then, there have been continuous efforts to develop safer vaccine techniques.

Currently, three main vaccines for smallpox are approved by FDA. Dryvax ${ }^{\circledR}$ was one of the main combinations used to eradicate smallpox in the early 20th century. Its production started in the 19th century in Wyeth Laboratories and was suspended in 1982 after global eradication was achieved. Dryvax ${ }^{\circledR}$ remained in stockpile till 2008 until it was replaced by ACAM2000, a second-generation vaccine with a safer, yet with the same efficacy profile [7]. The most recent smallpox vaccine is MVA-BN. It was approved in Europe and Canada in 2013 and the USA in 2019. MVA-BN has a better safety profile in comparison with Dryvax $^{\circledR}$ and ACAM2000 in patients with atopic dermatitis and immunodeficiency [8]. Although smallpox was eradicated, the Healthcare Infection Control Practices Advisory Committee and Advisory Committee on Immunization Practices recommend preoutbreak measures among certain high-risk groups [9].

\section{HPV}

Human Papillomavirus (HPV) is the most common cause of cervical cancer, the fourth most common cancer in women worldwide [10]. HPV was first detected in cervical cancer biopsies in 1983 [11]. Two decades later the earliest publication on the first HPV vaccine clinical trials was released. The first HPV vaccine was approved by the FDA in 2006 [10, 12]. Universal vaccination programs against HPV have resulted in a significant reduction in cervical cancer incidence and mortality. 


\section{Ebola viruses}

After the first Ebola virus disease epidemic was documented in 1976 in West Africa, multiple short-term explosive outbreaks occurred with variable severity. The deadliest and latest outbreak was in 2014 with a case fatality rate of up to $85 \%$. This led the WHO to declare the epidemic as an international public health emergency in August 2014 [13-14]. Before that, multiple non-human trials were underway to develop a vaccine against the Ebola virus family [15]. In 2015, the race to create a safe and effective vaccine began, and many human clinical trials were established to test multiple vaccine candidates [16].

For rapid safety and immunogenicity testing, a replication-competent recombinant vesicular stomatitis virus (rVSV)-based vaccine expressing a Zaire ebolavirus (ZEBOV) glycoprotein was used [16]. Under the brand name Ervebo ${ }^{\circledR}$, it was authorized by the European Medicines Agency (EMA) in Nov 2019 and by the FDA in Dec 2019 [17-18]. The second vaccine is the two-dose heterologous Ad26.ZEBOV and MVA-BN-Filo Ebola vaccine regimens, which are two different vaccines given about 56 days apart. It was approved for medical use by EMA in July 2020 [14, 19-20]. While many vaccines are still under trial, those are the only approved vaccines against the Ebola family of viruses.

\section{Rotavirus}

Rotavirus was first discovered in 1973 and was found to be the major causative agent of acute gastroenteritis in childhood. Several clinical trials phase I-III have been conducted since 1981 to develop a safe vaccine against Rotavirus. The first FDA-approved vaccine was licensed under the brand name Rotashield ${ }^{\circledR}$ in 1998 , but it was withdrawn in less than a year because of a proven association with intussusception. It took another eight years, till a safer vaccine against rotavirus was licensed. In 2006, RotaTeq ${ }^{\circledR}$ (RV5: Pentavalent) was introduced into the universal vaccination program in the USA. Then, Rotarix ${ }^{\circledR}$ (RV1: Monovalent) was licensed by FDA in 2008 [21]. A meta-analysis of multiple case-control studies in the United States, comparing the effectiveness of different rotavirus vaccine types, did not show a statistically significant difference [5].

\section{Hepatitis A virus}

The Hepatitis A virus was first detected in the United States in 1973. It took three decades to develop a safe and effective vaccine against it. The first vaccine against Hepatitis A was called Havrix ${ }^{\circledR}$ and was licensed in 1992. This was followed by the vaccine Vaqta ${ }^{\circledR}$ which was licensed in 1993 . Those are the only licensed vaccines against the Hepatitis A virus in the United States [22-23].

\section{Haemophilus influenzae}

Haemophilus influenzae was first described in 1892. Initially, it was mistakenly considered as the cause of Influenza pandemics, until in 1933 when the viral etiology was revealed [24-25]. It is responsible for a wide range of localized and invasive infectious diseases. It is classified into capsulated and nonencapsulated variants. The capsulated was subclassified into six serotypes a-f according to the capsular antigens. The most virulent and invasive serotype is the type $b$ strain (Hib). The first vaccine developed against Hib was in the early 1970s in Finland. It was composed of the capsular polysaccharide capsule polyribosylribitol phosphate (PRP). Pure polysaccharide vaccines were first licensed in the United States in 1985 and recommended for those over 18 months. Studies showed no efficacy of PRP vaccines in ages below 18 months due to the immaturity of the immune system. It was used until 1988 when it was shown that conjugate vaccines are better in inducing an immune response in infancy which is considered the peak age for invasive Hib infections. The PRP attachment to a protein conjugate as tetanus and diphtheria toxoids was the initial step for developing conjugate vaccines. Currently, the licensed products are combinations with other vaccine products such as Hepatitis B and Diphtheria Pertussis Tetanus vaccines [26].

\section{Influenza}

The exact timing of influenza pandemics is not known exactly. The earliest Influenza-like illness was mentioned by Hippocrates in 400 BC, in the "Book of Epidemics", however, not all researchers think that this was actually influenza. The first pandemic that certainly matched the current description of influenza was documented in 1580 [27]. Since then, multiple influenza pandemics have occurred throughout the world. One of the most devastating pandemics was the "Spanish flu" in 1918 which caused tens of millions of deaths. It was mistakenly thought that the pandemic had a bacterial etiology, until 1931 when the influenza virus was isolated from nasal secretions of infected patients. The first trials to develop a vaccine were in the mid-1930s. In 1938 a successful experiment to develop a monovalent inactivated vaccine was conducted to protect the US military against the Influenza A virus. The vaccine was approved for public use in the United States in 1945. Soon a new strain "Influenza B" was discovered, and a few years later the first bivalent vaccine was licensed for public use [27].

The antigenic shifts and drifts and continuous changes in the virus compositions necessitated the establishment of a surveillance system for the circulating influenza strains. The first surveillance was created by the WHO in 1952. The discovery of newer strains and the different types of hemagglutinin and neuraminidase antigens in different pandemics all over the world lead to the introduction of the Trivalent 
vaccine in the 1970s. Subsequently, the Quadrivalent vaccine was licensed by the FDA in 2012.

Advancements in cell culture techniques, recombinant DNA, and whole genome sequencing gave scientists the ability to rapidly respond to the evolving Influenza pandemics like the "Avian flu" in 1997 and the "Swine flu” in 2009, by creating safe and effective vaccines within a few months. Current research priorities include the development of universal vaccines that can respond to the current and evolving strains [27].

\section{COVID-19}

The first reported cases of COVID-19 were in Dec 2019 in Wuhan, China. A cluster of patients with unexplained respiratory infections was shown to be caused by a novel coronavirus named SARS-CoV-2 [2830]. This virus belongs to the Coronaviridae family which also includes the severe acute respiratory syndrome coronavirus-1 (SARS-CoV-1) and Middle East respiratory syndrome coronavirus (MERS-CoV). COVID-19 was declared as a pandemic by WHO on March 11th, 2020 [31-32]. Fever, myalgia, cough, dyspnea, and flulike symptoms are the most frequent symptoms of COVID-19, which predominantly affects the respiratory system. From asymptomatic infection to respiratory failure, multi-organ dysfunction, and death, the COVID-19 has a wide spectrum of clinical presentations [33]. COVID-19 has been linked to harmful effects on other body systems in addition to the respiratory system [34-38]. Although SARS-CoV-2 has a lower mortality rate in comparison with SARS-CoV and MERS-CoV, the transmissibility and spread are much higher than SARS-CoV-1 and MERS. In early 2020, the race for developing an effective and safe vaccine began. Soon there were more than 200 candidates in preclinical and clinical development all over the world. A fewer number reached phase III of the clinical trials, and in Dec 2020 the first COVID-19 vaccine, created through a collaboration of Pfizer and BioNTech, was approved. COVID-19 vaccine development is considered one of the fastest in the history of vaccine science. SARS-CoV-1 and MERS vaccine candidates did not go beyond phase I because of the limited spread of the disease and diminished demand, but they helped to understand how the body reacts to coronaviruses [39]. On Dec 31st, 2020 the WHO issued an Emergency Use Listing (EULs) for the Pfizer COVID-19 vaccine (mRNA vaccine). On Feb 15th, 2021 the WHO issued a EUL for the AstraZeneca/Oxford COVID-19 vaccine (Adenovirus vector vaccine). On Mar 12th, 2021 the WHO issued a EUL for the Johnson \& Johnson COVID-19 vaccine (Adenovirus vector vaccine). Currently, those are the only vaccines issued by the EULs. Another mRNA vaccine manufactured by Moderna was licensed by FDA on Dec 18th, 2020, and the EMA on Jan 6th, 2021. While other vaccines are being distributed in other countries like Sinopharm, Coronavac, Novavax, and Sputnik vaccines, they are not included in the Emergency Use Listing issued by the WHO at the time of writing this article [40-41].

Different types of vaccines, their administration route, and their mechanism of action are summarized in Table 1. 


\section{Cureus}

\begin{tabular}{|c|c|c|c|c|c|}
\hline Disease agent & $\begin{array}{l}\text { Year } \\
\text { identified }\end{array}$ & Vaccine name & $\begin{array}{l}\text { Year licensed } \\
\text { (FDA) }\end{array}$ & Vaccine type & $\begin{array}{l}\text { Route of } \\
\text { administration }\end{array}$ \\
\hline \multirow{4}{*}{ Smallpox } & \multirow{4}{*}{$300 \mathrm{AD}$} & $\begin{array}{l}\text { Vaccine by Edward } \\
\text { Jenner }\end{array}$ & 1796 & $\begin{array}{l}\text { Extract of cowpox lesions on } \\
\text { milkmaids' hands. }\end{array}$ & Skin punctures \\
\hline & & Dryvax & $\begin{array}{l}\text { Late } 19^{\text {th }} \text { century } \\
\text { (withdrawn) }\end{array}$ & Lyophilized, live-virus preparation & $\begin{array}{l}\text { Bifurcated needle } \\
\text { punctures }\end{array}$ \\
\hline & & ACAM2000 & 2007 & Cell cultured, Live virus & $\begin{array}{l}\text { Bifurcated needle } \\
\text { punctures }\end{array}$ \\
\hline & & MVA-BN & 2013 & Recombinant & IM \\
\hline \multirow{4}{*}{$\begin{array}{l}\text { Haemophilus } \\
\text { influenza }\end{array}$} & \multirow{4}{*}{1933} & Hib & 1985 (withdrawn) & $\begin{array}{l}\text { Capsular polysaccharide } \\
\text { capsule polyribosylribitol phosphate }\end{array}$ & IM \\
\hline & & PedvaxHIB & 1990 & Meningococcal protein conjugate & IM \\
\hline & & ActHIB & 1993 & Tetanus toxoid conjugate & IM \\
\hline & & Hiberix & 2009 & Tetanus toxoid conjugate & IM \\
\hline \multirow{4}{*}{ Influenza } & \multirow{4}{*}{1933} & $1^{\text {st }}$ Bivalent & 1945 & Inactivated & IM \\
\hline & & $1^{\text {st }}$ Trivalent & 1978 & Inactivated & IM \\
\hline & & FluMist & 2004 & Live attenuated vaccine & Intranasal \\
\hline & & $1^{\text {st }}$ Quadrivalent & 2012 & Inactivated & IM \\
\hline \multirow{2}{*}{$\begin{array}{l}\text { Hepatitis A } \\
\text { virus }\end{array}$} & \multirow{2}{*}{1973} & Havrix & 1992 & Inactivated & IM \\
\hline & & VAQTA & 1993 & Inactivated & IM \\
\hline \multirow{3}{*}{ Rotavirus } & \multirow{3}{*}{1973} & Rotashield & 1998 (withdrawn) & & \\
\hline & & RotaTeq & 2006 & Live virus & Oral \\
\hline & & ROTARIX & 2008 & Live virus & Oral \\
\hline Ebola virus & 1976 & ERVEBO & 2019 & Live virus & IM \\
\hline HPV & 1983 & Gardasil & 2006 & Recombinant & IM \\
\hline \multirow{7}{*}{ COVID-19* } & \multirow{7}{*}{2019} & Pfizer-BioNTech & Dec 2020 & mRNA vaccine & IM \\
\hline & & AstraLeneca/Oxtord & Feb 2021 & Adenovirus vector & IM \\
\hline & & Covishield & Feb 2021 & Adenovirus vector & IM \\
\hline & & Johnson \& Johnson & Mar 2021 & Adenovirus vector & IM \\
\hline & & Moderna & April 2021 & mRNA vaccine & IM \\
\hline & & Sinopharm-BBIBP & May 2021 & Inactivated & IM \\
\hline & & CoronaVac & June 2021 & Inactivated & IM \\
\hline
\end{tabular}

\section{TABLE 1: A summary of different types of vaccines.}

${ }^{*}$ COVID-19 vaccine license dates are provided based on WHO recommendations.

IM, intramuscular; HPV, human papillomavirus

\section{Conclusions}

Vaccines have played a crucial role in reducing the burden of infectious diseases. It all started with the initial inoculation efforts by the Chinese and the Indians 500 years ago. The journey of this practice traveled 
through the Ottomans and Africans landing in Europe and North America. When Edward Jenner's ideas laid the foundation for vaccination, he hoped that his work would eventually lead to the eradication of smallpox. Since then, it has been a long journey full of challenges and failures, but his hopes were finally realized when the World Health Assembly declared the world free of this disease in 1980. The body of knowledge for developing vaccines has kept on growing, and improvements in laboratory techniques have saved millions of lives. Furthermore, the unprecedented success of COVID-19 vaccines has added another weapon in the arsenal of evidence that we have for the effectiveness of vaccines. Each vaccine has a unique developmental history and studying it can provide much-needed wisdom that might help us in future pandemics. Thus, we wanted to use this opportunity to share the results of our in-depth investigation of the development of various vaccines throughout history.

\section{Additional Information \\ Disclosures}

Conflicts of interest: In compliance with the ICMJE uniform disclosure form, all authors declare the following: Payment/services info: All authors have declared that no financial support was received from any organization for the submitted work. Financial relationships: All authors have declared that they have no financial relationships at present or within the previous three years with any organizations that might have an interest in the submitted work. Other relationships: All authors have declared that there are no other relationships or activities that could appear to have influenced the submitted work.

\section{References}

1. Artenstein AW, Poland GA: Vaccine history: the past as prelude to the future . Vaccine. 2012, 30:5299-5301. 10.1016/j.vaccine.2012.06.060

2. Boylston A: The origins of inoculation. J R Soc Med. 2012, 105:309-313. 10.1258/jrsm.2012.12k044

3. Delany I, Rappuoli R, De Gregorio E: Vaccines for the 21st century. EMBO Mol Med. 2014, 6:708-720. 10.1002/emmm.201403876

4. History of smallpox. (2021). Accessed: April 7, 2021: https://www.cdc.gov/smallpox/history/history.html.

5. Pindyck T, Tate JE, Parashar UD: A decade of experience with rotavirus vaccination in the United States vaccine uptake, effectiveness, and impact. Expert Rev Vaccines. 2018, 17:593-606. 10.1080/14760584.2018.1489724

6. Sánchez-Sampedro L, Perdiguero B, Mejías-Pérez E, García-Arriaza J, Di Pilato M, Esteban M: The evolution of poxvirus vaccines. Viruses. 2015, 7:1726-1803. 10.3390/v7041726

7. Nalca A, Zumbrun EE: ACAM2000: the new smallpox vaccine for United States Strategic National Stockpile . Drug Des Dev Ther. 2010, 4:71-79.10.2147/dddt.s3687

8. Volkmann A, Williamson AL, Weidenthaler H, et al.: The Brighton Collaboration standardized template for collection of key information for risk/benefit assessment of a Modified Vaccinia Ankara (MVA) vaccine platform. Vaccine. 2021, 39:3067-3080. 10.1016/j.vaccine.2020.08.050

9. Wharton M, Strikas RA, Harpaz R, et al.: Recommendations for using smallpox vaccine in a pre-event vaccination program. Supplemental recommendations of the Advisory Committee on Immunization Practices (ACIP) and the Healthcare Infection Control Practices Advisory Committee (HICPAC). MMWR Recomm Rep. 2003, 52:1-16.

10. Castle PE, Maza M: Prophylactic HPV vaccination: past, present, and future . Epidemiol Infect. 2016, 144:449-468. 10.1017/S0950268815002198

11. Dürst M, Gissmann L, Ikenberg H, zur Hausen H: A papillomavirus DNA from a cervical carcinoma and its prevalence in cancer biopsy samples from different geographic regions. Proc Natl Acad Sci USA. 1983, 80:3812-3815.

12. Brown DR, Fife KH, Wheeler CM, et al.: Early assessment of the efficacy of a human papillomavirus type 16 L1 virus-like particle vaccine. Vaccine. 2004, 22:2936-2942. 10.1016/j.vaccine.2003.11.059

13. Statement on the 1st meeting of the IHR Emergency Committee on the 2014 Ebola outbreak in West Africa . (2014). Accessed: April 11, 2021: https://www.who.int/news/item/08-08-2014-statement-on-the-1stmeeting-of-the-ihr-emergency-committee-on-the-2014-ebol....

14. Pollard AJ, Launay O, Lelievre JD, et al.: Safety and immunogenicity of a two-dose heterologous Ad26.ZEBOV and MVA-BN-Filo Ebola vaccine regimen in adults in Europe (EBOVAC2): a randomised, observer-blind, participant-blind, placebo-controlled, phase 2 trial. Lancet Infect Dis. 2021, 21:493-506. 10.1016/s1473-3099(20)30476-x

15. Henao-Restrepo AM, Longini IM, Egger M, et al.: Efficacy and effectiveness of an rVSV-vectored vaccine expressing Ebola surface glycoprotein: interim results from the Guinea ring vaccination cluster-randomised trial. Lancet. 2015, 386:857-866. 10.1016/s0140-6736(15)61117-5

16. Agnandji ST, Huttner A, Zinser ME, et al.: Phase 1 trials of rVSV ebola vaccine in Africa and Europe . N Engl J Med. 2016, 374:1647-1660.

17. Ervebo EPAR. (2019). Accessed: April 11, 2021: https://www.ema.europa.eu/en/medicines/human/EPAR/ervebo.

18. First FDA-approved vaccine for the prevention of Ebola virus disease . (2019). Accessed: April 11, 2021: https://www.fda.gov/news-events/press-announcements/first-fda-approved-vaccine-prevention-ebolavirus-disease-marking....

19. Mvabea. (2020). Accessed: April 11, 2021: https://www.ema.europa.eu/en/medicines/human/EPAR/mvabea.

20. Zabdeno. (2020). Accessed: April 11, 2021: https://www.ema.europa.eu/en/medicines/human/EPAR/zabdeno.

21. Vesikari T: Rotavirus vaccination: a concise review. Clin Microbiol Infect. 2012, 18:57-63. 10.1111/j.14690691.2012.03981.x 
22. Shouval D: The history of hepatitis A. Clin Liver Dis (Hoboken). 2020, 16:12-23. 10.1002/cld.1018

23. Zhang L: Hepatitis A vaccination. Hum vaccine Immunother. 2020, 16:1565-1573. 10.1080/21645515.2020.1769389

24. Kuhnert P, Christensen H: Pasteurellaceae: Biology, Genomics and Molecular Aspects. Kuhnert P, Christensen H (ed): Caister Academic Press, United Kingdom; 2008.

25. Chandrasekharan S, Amin T, Kim J, Furrer E, Matterson AC, Schwalbe N, Nguyen A: Intellectual property rights and challenges for development of affordable human papillomavirus, rotavirus and pneumococcal vaccines: patent landscaping and perspectives of developing country vaccine manufacturers. Vaccine. 2015, 33:6366-6370. 10.1016/j.vaccine.2015.08.063

26. WHO Immunological Basis for Immunization Series: Module 9: Haemophilus influenzae type b . (2007). Accessed: April 16, 2021: https://www.who.int/publications/i/item/who-immunological-basis-forimmunization-series-module-9-haemophilus-influenz....

27. Barberis I, Myles P, Ault SK, Bragazzi NL, Martini M: History and evolution of influenza control through vaccination: from the first monovalent vaccine to universal vaccines. J Prev Med Hyg. 2016, 57:E115-E120.

28. Singh R, Rathore SS, Khan H, et al.: Mortality and severity in COVID-19 patients on ACEIs \& ARBs - a metaregression analysis [PREPRINT]. medRxiv. 2021, 10.1101/2021.03.14.21253557

29. Singh R, Shaik L, Mehra I, Kashyap R, Surani S: Novel and controversial therapies in COVID-19. Open Respir Med J. 2020, 14:79-86. 10.2174/1874306402014010079

30. Singh R, Rathore SS, Khan H, et al.: Association of obesity with COVID-19 severity and mortality: a systemic review and meta-regression [PREPRINT]. medRxiv. 2021, 10.1101/2021.05.08.21256845

31. Bansal V, Mahapure KS, Bhurwal A, et al.: Mortality benefit of remdesivir in COVID-19: a systematic review and meta-analysis. Front Med (Lausanne). 2020, 7:606429. 10.3389/fmed.2020.606429

32. Bansal V, Mahapure KS, Mehra I, et al.: Mortality benefit of convalescent plasma in COVID-19: a systematic review and meta-analysis. Front Med (Lausanne). 2021, 8:624924. 10.3389/fmed.2021.624924

33. Karale S, Bansal V, Makadia J, et al.: A meta-analysis of mortality, need for ICU admission, use of mechanical ventilation and adverse effects with ivermectin use in COVID-19 patients [PREPRINT]. medRxiv. 2021, 10.1101/2021.04.30.21256415

34. Menon T, Sharma R, Kataria S, et al.: The association of acute kidney injury with disease severity and mortality in COVID-19: a systematic review and meta-analysis. Cureus. 2021, 13:e13894. 10.7759/cureus.13894

35. Singh R, Shiza ST, Saadat R, Dawe M, Rehman U: Association of Guillain-Barre Syndrome with COVID-19: a case report and literature review. Cureus. 2021, 13:e13828. 10.7759/cureus.13828

36. Menon T, Sharma R, Earthineni G, et al.: Association of gastrointestinal system with severity and mortality of COVID-19: a systematic review and meta-analysis. Cureus. 2021, 13:e13317. 10.7759/cureus.13317

37. Singh R, Kashyap R, Hutton A, Sharma M, Surani S: A review of cardiac complications in coronavirus disease 2019. Cureus. 2020, 12 :e8034. 10.7759/cureus.8034

38. Rathore SS, Rojas GA, Sondhi M, et al.: Myocarditis associated with Covid-19 disease: a systematic review of published case reports and case series [PREPRINT]. Authorea Preprints. 2021, 10.22541/au.161219538.89676033/v1

39. Singh R, Kang A, Luo X, Jeyanathan M, Gillgrass A, Afkhami S, Xing Z: COVID-19: current knowledge in clinical features, immunological responses, and vaccine development. FASEB J. 2021, 35:21409. 10.1096/fj.202002662R

40. COVID-19 vaccine Moderna. (2021). Accessed: April 17, 2021: https://www.ema.europa.eu/en/medicines/human/EPAR/covid-19-vaccine-moderna

41. Coronavirus disease (COVID-19): vaccines. (2020). Accessed: April 17, 2021: https://www.who.int/newsroom/q-a-detail/coronavirus-disease-(covid-19)-vaccines. 